\title{
Los Tribunales Administrativos especiales en Chile
}

\author{
Ezio Costa Cordella*
}

\begin{abstract}
RESUMEN
Los Tribunales Administrativos Especiales, es decir, aquellos organismos que han sido creados para la revisión de actos administrativos de carácter sectorial, surgen desde la orfandad que deja la ausencia de tribunales contencioso-administrativos. La presión por revisar actos de la Administración, mientras esta se ha vuelto cada vez más específica, compleja e intensa en su regulación, ha supuesto la necesidad de crear órganos que puedan abordar este fenómeno. En su creación renace la discusión en torno a los límites de la revisión de los actos, confrontándose aquí las posturas contrapuestas de la doctrina de la luz roja y la luz verde del derecho administrativo por una parte, y desafiándose la separación de poderes, por otra. En este debate se enmarca por ejemplo el gran consenso detrás de la creación de Tribunales Ambientales y su cuestionada naturaleza por parte de la Corte Suprema. Los tribunales administrativos especiales aparecen boy como una solución ecléctica, pero que no aborda de manera integral el problema del control judicial de los actos administrativos, especialmente por la falta de representación de los usuarios, consumidores y comunidades en la discusión.
\end{abstract}

Tribunales Especiales - contencioso - administrativo - discrecionalidad

\section{Special Administrative Courts in Chile}

\begin{abstract}
The Special Administrative Courts, created for the judicial review of administrative acts that are sector-specific, arise from the lack of general administrative courts. Their creation has been demanded in response to the increasingly specific, complex and intense regulation of the administrative apparatus. In these instances, the discussion about the limits of the judicial review is revisited in the conflicting positions of the doctrine of the red light and the green light of administrative law, on the one hand, and the challenge to the separation of powers, on the other hand. This debate frames, for instance, the large consensus bebind the creation of Environmental Courts and the challenge of their nature by the Supreme Court. The special administrative courts appear today as an eclectic solution, that does not systematically address the problem of judicial review of administrative acts. This is due in particular to the lack of participation of users, consumers and communities in the discussion.
\end{abstract}

Keywords: Special Courts - Administrative litigation - Discretion

* Abogado, Universidad de Chile. Pio Nono No 1, Cuarto Piso, Centro de Regulación y Competencia, Providencia.ecosta@derecho.uchile.cl. Investigador Centro de Regulación y Competencia (RegCom), Universidad de Chile. Director Ejecutivo, Corporación FIMA.

Artículo recibido el 5 de septiembre de 2013 y aceptado para su publicación por el Comité Editorial el 28 de mayo de 2014 . 


\section{INTRODUCCIÓN}

$\mathrm{E}$ 1 estudio de los Tribunales Administrativos Especiales cobra relevancia en un momento en que se han vuelto muy abundantes en nuestro entramado institucional, suscitando cierto nivel de polémica entre los poderes del Estado. El presente estudio tiene como centro de sus ejemplos la creación de los Tribunales Ambientales, por recientes y porque en dicha discusión se pudo observar las discrepancias que subyacen a la creación de estos tribunales, y por lo tanto sirve como hilo conductor del análisis del presente artículo. El análisis que se realizará será principalmente desde la clave del poder, en una doble matriz; por una parte en el eje Poder Ejecutivo-Legislativo-Judicial, y por otra parte en el eje Estado-Privados 1 (regulados)Privados 2 (usuarios, consumidores y comunidades), como veremos.

Al hablar de Tribunales Administrativos Especiales la referencia es a aquellos organismos que han sido creados para la revisión de actos administrativos de carácter sectorial y que se encuentran fuera del Poder Judicial. Tomamos en parte la clasificación de Tribunales Administrativos que hace Ferrada, quien los divide en: (i) Tribunales Ordinarios con Competencias Administrativas, Órganos Administrativos con Competencias Jurisdiccionales y Tribunales Especiales de Justicia Administrativa ${ }^{1}$.

Sin embargo, se excluye de esta última categoría a aquellos tribunales que se encuentran dentro del Poder Judicial, los cuales para Ferrada conviven con aquellos que están fuera de él. Si bien se entiende que el autor los incluye por ser tribunales con competencias específicas, nos parece más acertado solo incluir aquellos que están fuera del Poder Judicial, considerando que los que están dentro de él (como los Juzgados de Letras del Trabajo), aun cuando sean especiales dentro del orden del Poder Judicial, desde el punto de vista del derecho administrativo debieran caber en la categoría de Tribunales Ordinarios. Esto es especialmente importante en Chile donde aún habiendo un juez común, son muchos los Tribunales Ordinarios con competencias especiales.

Los Tribunales Administrativos Especiales, en palabras de Ferrada, son aquellos tribunales especiales competentes para conocer de las reclamaciones o impugnaciones a la legalidad de un acto de la Administración del Estado en ámbitos específicos, los que han sido creados por el legislador en cada caso ${ }^{2}$. A lo que agregamos, como hemos dicho, que se encuentran fuera del Poder Judicial.

Son por ejemplo el Tribunal de Defensa de la Libre Competencia (TDLC), los Tribunales Tributarios y Aduaneros, el Tribunal de Compras y Contratación Pública, el Tribunal de Propiedad Industrial y los Tribunales Ambientales ${ }^{3}$.

\footnotetext{
${ }^{1}$ Ferrada, J.C., "Los Tribunales que ejercen la justicia administrativa en el derecho chileno", en Arancibia Mattar y otros (coord.), Litigación Pública, Thomson Reuters, Santiago, 2011. p. 119-150.

${ }^{2}$ Ibíd. p. 133.

${ }^{3}$ Excluyo del grupo a organismos como el Consejo para la Transparencia y el Panel de Expertos de la Ley General de Servicios Eléctricos, por no estar sujetos a la superintendencia de la Corte Suprema y considerando que para que ellos integrasen este grupo debiera discutirse su calidad de tribunales, cuestión que excede este trabajo.
} 
Entre ellos hay diferencias notorias no solo desde el punto de vista de la especificidad de sus competencias, sino que también en su composición, independencia, relación con los demás poderes del Estado, formas de conocer de los asuntos y otros, siendo incluso posible adentrarse en la discusión de cuáles de ellos son propiamente tribunales y cuáles no lo son, de acuerdo con, entre otras cosas, si ejercen o no jurisdicción ${ }^{4}$.

Pero dentro de sus notorias diferencias, estos organismos comparten una raíz común en lo que motivó su creación, así como el hecho de funcionar principalmente como revisores de actuaciones de la administración. En la práctica, además, han venido a suplir la inexistencia de tribunales contencioso-administrativos y con ello a dar -en algunas áreas- una vía institucional un poco más orgánica a la solución de conflictos administración-administrado.

\section{La falta de un Contencioso Administrativo unificado: Evolución del Procedimiento Contencioso Administrativo en Chile}

Quienes creen que la justicia administrativa debe estar radicada en tribunales contencioso-administrativos diferentes de los tribunales ordinarios parten en general del concepto y principio de separación de poderes y en particular de la aplicación que de este se hizo luego de la Revolución Francesa, donde le fue impedido a los jueces comunes conocer de los asuntos entre los ciudadanos y la administración, por considerar que al hacerlo se inmiscuían en cuestiones propias de gobierno (hoy diríamos de política pública) que no les correspondían 5 .

La objeción al ingreso del juez generalista a cuestiones de política pública obedece a una consideración de la democracia, en la que la decisión tomada por la Administración que ha sido elegida democráticamente debe tener un peso específico mucho mayor que la consideración que de dicha decisión tenga un juez, funcionario llamado a aplicar la ley y que no goza de la legitimidad de una elección popular. En ese sentido entonces, la revisión de las actuaciones de la administración en el mejor de los casos debería llevarse a cabo por un organismo especializado, pero no por la el juez generalista.

Un camino cercano a ese concepto fue el que tomó Chile en la Constitución de 1833, que al decir de Ferrada plasmó gran parte del ideario político republicano autoritario de esos años ${ }^{6}$, y que fue guiando también el actuar institucional durante el siglo XX, previo al quebrantamiento de la institucionalidad. En esa Constitución se instituyó un Consejo de Estado, inspirado notoriamente en la realidad francesa posrevolucionaria, como lo consigna Vergara Blanco: En la Constitución de 1833 en un principio se reconoció

\footnotetext{
${ }^{4}$ En esta discusión, por todos Greiber, B., Ocampo, L. y Seguel, L., "Justicia Tributaria y delegación de facultades jurisdiccionales: Análisis de la Jurisprudencia reciente del Tribunal Constitucional”, en Sentencias Destacadas 2006, Instituto Libertad y Desarrollo, Santiago, 2006, pp. 231-270.

${ }^{5}$ Ferrada, J.C., “Justicia Administrativa y Principio de Separación de Poderes”, en Estudios de Derecho Público, Actas de las XL Jornadas de Derecho Público, Legal Publishing, 2010, pp. 284-291.

${ }^{6}$ Ibid. p. 292.
} 
competencia en materias de esta naturaleza al Consejo de Estado, creyendo algunos autores de la época que con esto se tendía a adoptar el sistema imperante en Francia, vale decir, la tendencia a encargar el conocimiento de contiendas de naturaleza administrativa a una jurisdicción especial ${ }^{7}$.

Casi un siglo después, sin embargo, se produjo un cisma contenido con la dictación de la Constitución de 1925, ya que ella crea tribunales especializados en materias administrativas, cuales son los tribunales contencioso-administrativos. Dichos tribunales siguen bajo el concepto revolucionario de que el conocimiento de las controversias entre administración y administrado debe ser llevado adelante por un tribunal especial, pero se distinguen claramente de las soluciones francesas en cuanto son tribunales que están dentro del Poder Judicial ${ }^{8}$.

La contención del cisma vino no solo por el lado de entregar a tribunales especializados el conocimiento de los asuntos contencioso-administrativos, sino que además y principalmente, por el hecho de que a pesar del mandato del constituyente de 1925 los tribunales administrativos nunca fueron efectivamente creados e instalados. Para colmo, a la renuencia del legislador para crear estos tribunales se unía la jurisprudencia sostenida de los tribunales civiles en el sentido de no admitir demandas con sustento administrativo, salvo casos aislados. En este sentido Faúndez señala que durante el período de la democracia de partidos, en las raras ocasiones en que la Corte desafió al gobierno, lo bizo invocando mecánicamente la inviolabilidad de la propiedad y del contrato ${ }^{9}$.

La Constitución de 1980 no vino a cambiar radicalmente ese escenario en principio, porque mantuvo en su redacción la mención a los tribunales contencioso-administrativos. Sin embargo, sí tuvo visos de cambio en cuanto fue redactada de tal manera que los asuntos recayeran en la jurisdicción ordinaria a falta de dichos tribunales. Subyacía tal vez una idea realista, ya que si en 55 años de vigencia de la Constitución de 1925 los tribunales no habían sido creados, era esperable que ahora tampoco lo fueran, y efectivamente así ocurrió.

El cambio definitivo en la manera de abordar el problema se dio con la reforma de 1989 a dicha Constitución, y la eliminación de la mención a los tribunales contenciosoadministrativos. En palabras de Urbano Marín, la citada reforma constitucional de 1989, que eliminó la referencia a los tribunales contencioso-administrativos en el artículo 38 de la Carta Politica de 1980, ha alejado indefinidamente la posibilidad de contar con una justicia especial en lo administrativo. Ella tampoco se compensó con la implantación de un procedimiento contencioso-administrativo, al abrir la competencia en este campo de la Justicia Ordinaria ${ }^{10}$.

Las palabras de Urbano Marín, pronunciadas en 2002, parecen seguir retumbando en las salas de los tribunales superiores de justicia, en cuanto recientemente la Corte Suprema, por medio de su presidente Milton Juica y a propósito de la inauguración del

${ }^{7}$ Vergara, A., "Esquema del Contencioso-Administrativo: Su tendencia hacia un modelo mixto", en Arancibia Mattar y otros (coord.), Litigación Pública, Thomson Reuters, Santiago, 2011, p. 42.

${ }^{8}$ Ibíd. p. 295.

${ }^{9}$ Faúndez J., Democratización, Desarrollo y Legalidad. Ediciones Diego Portales, Santiago, 2011, p. 152.

${ }^{10}$ Marín, U., "Vigencia actual de la invalidación de los actos administrativos", en Revista de Derecho del Consejo de Defensa del Estado, N², Santiago, 2002, p. 2. 
año judicial 2011, expresó su preocupación porque se legisle en el sentido de unificar el procedimiento contencioso-administrativo ${ }^{11}$.

La revisión de los actos administrativos fue dejada entonces en la orfandad, mendigando la posibilidad de ser conocida por los jueces de instancia mediante acciones creadas doctrinariamente como la nulidad de derecho público o utilizando una vía que no había sido concebida expresamente para ello como el Recurso de Protección y esperando en ambos casos que los tribunales se plegaran a la posibilidad de conocer de estas causas a base principalmente de la inexcusabilidad y al que la Constitución señalara en su artículo 38 inciso segundo que cualquier persona que sea lesionada en sus derechos por la Administración del Estado, de sus organismos o de las municipalidades, podrá reclamar ante los tribunales que determine la ley, sin perjuicio de la responsabilidad que pudiere afectar al funcionario que bubiere causado el daño.

Lo anterior también por cuanto la enmienda constitucional de 1989, aun cuando institucionalmente importante, no provocó ninguna revolución en materia de control de actos administrativos por parte de los tribunales, siendo estos aún renuentes o al menos muy deferentes a la hora de actuar. En este sentido Bordalí estima que en el caso de Chile esta evolución ha sido compleja. No ba sido el legislador el que se ha resistido mayormente a ser controlado por los tribunales de justicia, sino la Administración del Estado. Esta, arropada por el legislador y por la Corte Suprema y por el Tribunal Constitucional, ha evitado hasta hoy, con relativo éxito en muchos casos, ser controlada por la jurisdicción ${ }^{12}$.

Pero este escenario es cada vez más insostenible. La presión que existe por revisar actos de la administración ha aumentado en la medida que las actuaciones de la administración se han hecho más específicas y en algunos casos más intrusivas. Como señala Cordero Vega, este modelo ha sufrido una metamorfosis, puesto que de una administración burocrática-legal, como la descrita, se ha dado paso al modelo por él [Weber, M.] denominado 'politica administrativa', en que las normas simplemente marcan objetivos, resultados a obtener, siendo la Administración quien decide las premisas de actuaciones jurídicas, personales y organizativas para el logro de los mismos, lo que debe reorientar los instrumentos de control como se podrá apreciar ${ }^{13}$.

Esta posición mejorada de la Administración en la toma de decisiones que responde al avance del que algunos autores llaman Estado Regulador, ${ }^{14,}{ }^{15}$ implica un aumento

11 Juica, M. Discurso de Inauguración año judicial 2011. Disponible en http://www.pjud.cl/PDF/ Prensa_Com/CuentaPublica/discurso2011/discurso_1_de_marzo_2011.pdf?opc_menu=0\&opc_item =1 [última vista 30 de julio de 2012].

${ }^{12}$ Bordalí, A., "La Administración Pública ante los Tribunales de Justicia Chilenos", en Revista Chilena de Derecho, Vol. XXXIII, N 1 Pontificia Universidad Católica de Chile, Santiago, 2006, p. 18.

${ }^{13}$ Cordero, L., "El Control de la Administración del Estado”, $2^{a}$ Edición, Legal Publishing, Santiago, 2009 , pp. 14-15.

14 . Por todos, Baldwing, R., Cave, M.y Lodge, M., "Understanding Regulation. Theory, Strategy and Practice”, $2^{\text {nd }}$ Ed. Oxford University Press, Oxford, 2012, pp. 374-37.

${ }^{15}$ Dentro de las características del Estado Regulador está una separación institucional que implica la creación de organismos que están fuera de la lógica clásica de separación de poderes y que son independientes y tienen por objeto dar garantías que vayan más allá del proceso político, cuestión que en Chile se ha venido 
también de las posibilidades de que la administración actúe fuera de los límites que la ley y la Constitución le han impuesto, siendo por lo tanto más necesaria la existencia de las instancias suficientes de control en relación con ella, de manera de mantener dibujada una frontera entre las actividades que lícitamente puede llevar a cabo la administración y aquellas que no.

Sobre el particular, Cordero Vega pone su preocupación en las normas de procedimiento y de control en las leyes que otorgan mayores facultades a la administración, señalando que la indeterminación de la ley es más tolerable cuando dichos procedimientos y controles of recen garantías suficientes de que el proceso de concreción de la inicialmente vaga regulación legal se llevará a cabo de manera especialmente diligente y en condiciones de imparcialidad y no discriminación respecto de los distintos niveles implicados ${ }^{16}$.

Con todo, la necesidad de crear mecanismos de control de la Administración ha pasado a ser un tema importante en la agenda y la solución que se ha estado intentando ha sido la creación de Tribunales Administrativos Especiales, con las especificidades que veremos.

\section{El CONTROL DE LA DisCRECIONALIDAd ADMINISTRATIVA O LA DEFERENCIA A EXPERTO. El PROBlema “TÉCNICO”}

En la mayoría de los mensajes de las leyes que crean Tribunales Administrativos Especiales, y en sus discusiones, se habla de la necesidad de crearlos por cuanto los temas que abordan son de alta complejidad técnica y por lo tanto requeriría de personas altamente capacitadas en él para resolverlos.

Así por ejemplo el mensaje de la Ley $\mathrm{N}^{\circ} 19.911$, que crea el TDLC, expresa: El eje central del presente proyecto de ley es el fortalecimiento del órgano jurisdiccional encargado de resolver los conflictos en esta materia, el que pasa a denominarse Tribunal de Defensa de la Libre Competencia. El proyecto crea las condiciones necesarias para que las personas llamadas a analizar y decidir los posibles atentados a la libre competencia reúnan requisitos de excelencia profesional y alta dedicación, bajo un esquema de separación de funciones e independencia ${ }^{17}$, en el mismo sentido el mensaje de la Ley $\mathrm{N}^{\circ}$ 20.600, que expresa que el Tribunal propuesto está integrado por tres abogados y dos profesionales de las ciencias y la economía, siguiendo un estándar semejante al Tribunal de la Libre Competencia. La razón de esta integración está en que las cuestiones ambientales se mueven en un espacio de conocimiento altamente especializado, pero también incierto, por lo que no solo es razonable que puedan resolver las discrepancias los jueces

realizando, a medias. En este sentido; Cordero, L. y García, J.F., "Elementos para la discusión de Agencias Independientes en Chile”, en Anuario de Derecho Público, Universidad Diego Portales., Santiago, 2012, páginas 415-435.

${ }^{16}$ Ibid. p. 13.

${ }^{17}$ Biblioteca del Congreso Nacional. Historia de la Ley $\mathrm{N}^{\circ} 19.911$. p. 6. 
letrados, sino que también quienes no invisten tal calidad, pero que disponen de otra especialización que contribuye a una razonable y acabada decisión de los asuntos ambientales ${ }^{18}$.

Ahora bien, la supuesta necesidad de tener a profesionales de alta capacidad técnica resolviendo los problemas que se generan en algunas áreas, o por lo menos tener órganos especializados que solo se dediquen a los conflictos en esa determinada área es principalmente una consecuencia de la discusión en torno a la posibilidad de los tribunales ordinarios de conocer de las decisiones administrativas.

Esa discusión, más bien de derecho sustancial, se da por dos posturas contrapuestas, una de las cuales está por la posibilidad de una revisión amplia de las decisiones administrativas, o por el derecho administrativo de la luz roja, y otra que se inclina porque las decisiones de la administración si bien pueden ser revisadas por los tribunales ordinarios, esto solo puede ser en algunos aspectos procesales y de control de legalidad estricta, pero jamás de sustitución de la decisión del órgano; son quienes creen en el derecho administrativo de la luz verde ${ }^{19}$.

Tomás-Ramón Fernández y Eduardo García de Enterría son buenos expositores de quienes se inclinan por una revisión amplia de las decisiones administrativas. Señalan en efecto que siendo la aplicación de conceptos jurídicos indeterminados un caso de aplicación e interpretación de la ley que ha creado el concepto, el juez puede fiscalizar tal aplicación, valorando si la solución a que con ella se ha llegado es la única solución justa que la ley permite. Esta valoración parte de una situación de becho determinada, la que la prueba ofrece, pero su estimación jurídica la bace desde el concepto legal y es, por tanto, una aplicación de la ley. En cambio, el juez no puede fiscalizar la entraña de la decisión discrecional, puesto que, sea esta del sentido que sea, si se ha producido dentro de los límites de la remisión legal a la apreciación administrativa (y con respeto de los demás límites generales que veremos), es necesariamente justa (como lo serían igualmente la solución contraria) ${ }^{20}$.

De su opinión se desprende que validan lo que Saavedra llama control de la calificación jurídica de los hechos y que de acuerdo con su clasificación estaría muy cercano a la máxima posibilidad de control que es el control de la apreciación de los bechos. ${ }^{21}$ En efecto, el control por el que abogan los autores deja un núcleo muy pequeño de discrecionalidad, que será solo la toma de decisión atendida la oportunidad, economía y otras cuestiones de hecho. En este sentido, parece haber un acuerdo doctrinal en que la revisión judicial

\footnotetext{
${ }^{18}$ Biblioteca del Congreso Nacional. Historia de la Ley No 20.600. p. 11.

${ }^{19}$ Como señala Santiago Montt: La idea de un derecho administrativo de la luz roja y de la luz verde es original de Carol Harlow y Richard Rawlings, Law and Administration (3rd ed., Cambridge University Press, New York 2009), pp. 31 ss. La idea fue introducida en la primera edición de este texto de 1984. Montt, S., "Autonomía y responsividad: Dos expresiones de la vocación judificadora del Derecho Administrativo y sus principios fundamentales”. Documento de Trabajo para el Centro de Regulación y Competencia de la Facultad de Derecho de la Universidad de Chile, 2010. Disponible en http://www.regcom.uchile.cl/assets/files/Informes\%20y\%20 Papers/Documento\%20de\%20trabajo\%204.pdf [última vista $1^{\circ}$ de agosto de 2012].

${ }^{20}$ Fernández T. y García de Enterría, E., Curso de Derecho Administrativo, Tomo I, 1era edición, Civitas Ediciones, Buenos Aires, 2006, p. 467.

${ }^{21}$ Saavedra, R., Discrecionalidad Administrativa, Abeledo Perrot, Santiago 2011, pp. 117-120.
} 
no puede tocar el área de discrecionalidad administrativa discutiéndose más bien el radio de esa área.

En esa misma línea pero en la doctrina nacional, Pierry se inclina por una opción de aún mayor control de la discrecionalidad administrativa, en el sentido que la apreciación jurídica de los hechos, al igual que la verificación de su exactitud material, opera tanto para controlar los motivos legales como los motivos invocados. Es, no obstante, en este último caso donde cobra su real importancia como medio de controlar la discrecionalidad, ya que si la ley ha señalado expresamente los motivos por los cuales una decisión puede ser tomada, el control a través de la calificación jurídica de los hechos recaerá sobre el aspecto reglado de tal decisión, sin afectar al poder discrecional de la Administración que es el tema que nos preocupa ${ }^{22}$.

Por el otro lado, entre quienes defienden al derecho administrativo como un vehículo de satisfacción de necesidades sociales y que por lo mismo no creen en un control tan intenso de las decisiones administrativas destacamos a Luciano Parejo, quien cree que [e]n amplios sectores administrativizados de la vida social la programación o vinculación por parte de la ley formal es ya solo del tipo calificable de "relacional en función de fines-objetivos", que supone una abierta remisión de la decisión al escalón administrativo... ${ }^{23}$, y que por lo tanto siendo las decisiones sustantivas del derecho una cuestión que ha quedado en manos de la administración malamente podría aplicarse la solución judicialista, en tanto se pregunta: ¿por qué ha de quedar en manos del juez la última palabra (por sustitución de la administración) cuando una decisión simplemente se ha deslegalizado? ${ }^{24}$.

En la doctrina nacional, un buen expositor de la teoría de la luz verde es sin dudas Montt, para quien la teoría de la luz roja de derecho administrativo, (a) pesar de la astucia y sofisticación argumentativa del Derecho autónomo, el problema es radicalmente insuperable. Ocurre que, en un sistema democrático de gobierno, la política no es totalmente reductible al Derecho. La democracia es el gobierno de la mayoría y no el de los abogados ni menos de los jueces ${ }^{25}$.

En el fragor de esa disputa uno de los argumentos de quienes defienden un control mínimo de la discrecionalidad administrativa ha sido la existencia de cuestiones técnicas que no pueden ser revisadas por la judicatura ordinaria por falta de conocimientos, argumento que además ha sido cálidamente abrazado por los tribunales, dejando fuera de su control actos con este contenido y muchas veces olvidando con ello cualquier control. Así lo consigna Mario Galindo al señalar que desde el fallo Trillium que la jurisprudencia de la Corte Suprema es consistente en que debe resolver a base de ilegalidad o arbitrariedad y sin ver las bondades técnicas de un proyecto ${ }^{26}$.

22 Pierry, P., "El control de la Discrecionalidad Administrativa", en Revista de Derecho de la Pontificia Universidad Católica de Valparaíso, vol. VII, Valparaíso, 1984, p. 179.

23 Parejo, L., Administrar y Juzgar: dos funciones constitucionales distintas y complementarias, Tecnos, Madrid, 1993, p. 72.

${ }^{24}$ Ibid. p. 72.

${ }^{25}$ Montt, S. Ob. Cit.

${ }^{26}$ Galindo, M., El Caso Itata, "Sobre el control jurisdiccional de la discrecionalidad técnica a través del recurso de protección”, en Revista de Derecho Ambiental, vol. I, Facultad de Derecho Universidad de Chile, Santiago, 2003. p. 152. 
Por supuesto este concepto no es tranquilo, porque al utilizar los tribunales el estándar de discrecionalidad técnica, muchas veces lo que hacen es disfrazar la negativa a conocer de conflictos entre la administración y los administrados. En este sentido la queja de Mendoza al señalar: (B) asta de seguir arguyendo a la "discrecionalidad técnica", la "otra vía" o lo "complejo", puesto que ninguno de ellos son elementos que releven a la autoridad de lo propio, dar cuenta, cuando se le exija, del poder que se atribuye, y de ello ante el juez. Es, por lo demás, lo correcto en un Estado que se precie de Derecho ${ }^{27}$.

Ahora bien, aunque la discrecionalidad técnica sea solo una de las faces de la discrecionalidad administrativa, se ha puesto en el centro de la discusión relativa a la creación de Tribunales Administrativos Especiales porque pareciera ser una faz que permite llegar a una solución conjunta del problema de justiciabilidad contencioso-administrativa, siendo este argumento el que probablemente menos incomoda a los defensores de una mayor intervención judicial en el derecho administrativo, porque a pesar de que se intenta dejar fuera a la judicatura ordinaria del conocimiento de los asuntos contenciosoadministrativos, ello se hace no a base de consideraciones de legitimidad democrática o de derecho sustantivo, sino que por un problema práctico y que por lo tanto puede ser sorteado. Incluso más, la existencia de técnicos en los organismos revisores permite que la decisión de la administración sea eventualmente sustituida.

\section{La Creación de Tribunales Administrativos Especiales desde la visión del Poder Judicial}

Como dijimos, una de las características de los Tribunales Administrativos Especiales que estudiamos es que se encuentran fuera del Poder Judicial, aunque sujetos a la superintendencia de la Corte Suprema. Esto sin lugar a dudas significa de alguna manera tensar la relación entre los poderes del Estado al otorgarles facultades jurisdiccionales a organismos que no están dentro de dicho poder del Estado.

Ahora bien, esta tensión tiene también una cuestión doctrinaria en su sustrato, pues como vimos la discusión sobre si el control de la Administración del Estado debe ser realizada por tribunales o por organismos administrativos especiales, es una discusión centenaria. Por lo mismo, no es tan simple aseverar que al crearse Tribunales Administrativos Especiales se esté quitando competencias al Poder Judicial, aun cuando hoy tenga parte de ellas, máxime cuando no se observa en la perspectiva histórica que haya habido determinación para hacerse cargo de dichas competencias.

Sin perjucio de lo anterior, la preocupación es patente en los informes de la Corte Suprema a propósito de la creación de los Tribunales Ambientales, donde señala: esta Corte estima que en las condiciones en que el proyecto se propone, este no responde a los estándares mínimos para denominar tribunales a los órganos que se pretende crear. Se trata, en opinión del

${ }^{27}$ Mendoza, R., "Acerca del control de la discrecionalidad técnica en materia eléctrica”, en Revista Chilena de Derecho, volumen XXV, Pontificia Universidad Católica de Chile, Santiago, No 3, 1998, p. 720. 
Tribunal, de órganos administrativos y no jurisdiccionales, motivo por el cual se sugiere eliminar la expresión "tribunal" de los preceptos que la emplean ${ }^{28}$.

La Corte señala que si bien entre los poderes del Estado no existe una completa o absoluta separación de competencias como antiguamente se concebia... ${ }^{29}$; en este caso, en el proyecto que se somete al informe de esta Corte, no obstante lo dicho, se presenta un cambio radical al equilibrio anterior, pues se modifica el sistema constitucional de generación de los tribunales de justicia, baciendo intervenir en la fase del concurso a un servicio público conformado por personas elegidas por el Presidente de la República - el Consejo de Alta Dirección Pública-, que asume en definitiva casi la totalidad de las funciones y labores que corresponden a este Tribunal ${ }^{30}$.

El análisis de la Corte corresponde a lo que veníamos analizando a propósito de la historia del contencioso-administrativo en Chile y el celo por mantener ciertos límites entre los poderes del Estado, pero como decíamos, mirado históricamente se advierte una contradicción del tipo Perro del Hortelano, pues aun cuando durante largos pasajes el Poder Judicial se negó a conocer de las causas contencioso-administrativas y hasta hoy la deferencia a experto campea en muchas de nuestras Cortes, tampoco quisiera la Corte Suprema que las facultades de conocer de los conflictos contencioso-administrativos con alto contenido técnico quede entregada a estos Tribunales Administrativos Especiales y se aleje de su control.

Ahora bien, es muy posible que dicha contradicción tenga también que ver con las propias corrientes políticas y doctrinarias dominantes dentro del Poder Judicial, pues de otra forma es inexplicable que en 2011 la Corte Suprema se mostrara como el principal opositor a la creación de Tribunales Administrativos Especiales, señalando su presidente en el discurso inaugural de 2011 que es lo que está ocurriendo actualmente en nuestro país, con la frecuente creación de tribunales especiales, los que por su número debilitan el natural equilibrio que debe existir entre los poderes del Estado y atomiza peligrosamente la actividad jurisdiccional ${ }^{31}$. Se refería el ministro Juica precisamente a los tribunales que estamos estudiando, a los que agregaba los Paneles de Expertos.

Y luego en 2013, el actual presidente de la Corte Suprema, ministro Ballesteros, diga por el contrario, y a propósito de la entrada en funciones de los Tribunales Ambientales, que lo deseable es que en el futuro la gente, en lugar de recurrir a tribunales ordinarios de justicia, lo haga a los tribunales especiales ${ }^{32}$.

El análisis de la posición del Poder Judicial al respecto entonces no solo puede ser observada desde la lógica de la relación entre los poderes del Estado y de las potestades de cada uno de ellos, sino que en él también parece producirse la misma tensión que se

\footnotetext{
${ }^{28}$ Biblioteca del Congreso Nacional. Historia de la Ley $\mathrm{N}^{\circ} 20.600$, p. 633 y 1183.

${ }^{29}$ Ibid. p. 1332.

${ }^{30}$ Ibid. p. 1332.

31 Juica, M. Ob. Cit.

32 Entrevista a Rubén Ballesteros. Disponible en http://www.pulso.cl/noticia/empresa-mercado/ empresa/2013/06/11-23893-9-ruben-ballesteros-lo-deseable-es-que-las-materias-ambientales-se-resuelvanen.shtml [última vista 26 de julio de 2013].
} 
denota en el proceso histórico y en la discusión doctrinal sobre las competencias para decidir las controversias entre la administración y los administrados.

\section{Los Tribunales Administrativos Especiales: EL GRAN ACUERDO NACIONAL (Y SUS OLVIDOS)}

En el mensaje de la Ley $\mathrm{N}^{\mathrm{o}} 20.600$ que crea los Tribunales Ambientales es consciente de la disputa explicada anteriormente y resuelve, en este eclecticismo de acuerdo nacional: De toda la discusión que ha existido, en que algunos han criticado que el Estado supuestamente actúa como juez y parte en sus competencias de fiscalización y que otros señalan que este tipo de Tribunal es innecesario porque para ello existe la jurisdicción común, lo cierto es que lo importante es preguntarnos ¿qué es lo que se encuentra en juego detrás de la existencia de un Tribunal Ambiental? Las respuestas están vinculadas en nuestra opinión a los dilemas de eficiencia-eficacia de la regulación y la garantía de derechos de los regulados y de los ciudadanos en general ${ }^{33}$.

Los dilemas de eficiencia-eficacia de la regulación y de garantía son otra versión de los problemas de la luz verde y la luz roja, respectivamente, en cuanto el primero mira a las posibilidades del órgano administrativo regulador de hacer cumplir las regulaciones y el segundo a la posibilidad del administrado de asegurar que en ese enforcement se respeten sus derechos fundamentales, muy básicamente.

El propio mensaje de la Ley $\mathrm{N}^{\circ} 20.600$ identifica la creación de los tribunales ambientales como un punto de equilibrio entre estas dos miradas encontradas y en ese sentido dice que los sistemas democráticos, por un lado, dotando a los organismos administrativos de competencias regulatorias y de sanción ${ }^{34}$, pero sin olvidar que los jueces cumplen un rol esencial en el sistema de contrapesos de un sistema democrático, pero también tienen un rol esencial e insustituible en la protección de los derechos de las personas ${ }^{35}$.

$\mathrm{Y}$ por último, sin decir por qué entonces ese rol esencial de jueces no puede ser cumplido por la judicatura ordinaria, lo que sí hace es decir por qué debe ser realizada por una judicatura especializada, cuando explica su conformación, como vimos.

Así como el Tribunal Ambiental, la creación de Tribunales Administrativos Especiales es quizás la más ecléctica de las soluciones a la controversia entre administrativistas de la luz verde y la luz roja, porque permite la justiciabilidad de los actos administrativos con reglas especiales y con la presencia de especialistas.

Para los administrativistas de la luz roja, especialmente en Chile y ante la renuencia de los tribunales ordinarios a conocer estas materias, la creación de Tribunales Administrativos Especiales representa una victoria en cuanto con ellos se crean herramientas que permiten el control de los actos de la administración, y el desafío de la discrecionalidad de la misma. Siendo estos tribunales de composición mixta, la manera

\footnotetext{
33 Biblioteca del Congreso Nacional. Historia de la Ley $\mathrm{N}^{\circ} 20.600$, p. 7.

${ }^{34}$ Ibid. p. 10.

${ }^{35}$ Ibidem.
} 
de aplicar del derecho no será siempre y necesariamente igual a la de la administración, y debido al carácter técnico de sus integrantes se podría permitir la sustitución de la decisión administrativa y sin dudas se permite un mayor control del razonamiento técnico, así como una mayor certeza jurídica en el área regulada.

Para los administrativistas de la luz verde los Tribunales Administrativos Especiales son una buena señal porque sustraen, al menos en parte, el conocimiento de las controversias desde los tribunales ordinarios y las traslada a tribunales que son más parecidos al contencioso-administrativo, pues están especializados en temas administrativos y aún más especializados en los temas puntuales que atienden. Aumenta entonces la posibilidad de que estén alineados con la administración.

¿Todos ganan? No necesariamente. Digamos que el derecho administrativo de la luz verde está preocupado del Estado y el de la luz roja de los regulados y aunque los dos tienen cierta preocupación por el usuario, consumidor o comunidad, ninguno de los dos está pensado especialmente desde esa óptica ${ }^{36}$.

La creación de Tribunales Administrativos Especiales si bien favorecen a usuarios, consumidores y comunidades en el sentido de que también le otorgan nuevas herramientas jurídicas para enfrentarse tanto a la administración como a los regulados, también puede tener consecuencias que le sean desfavorables. Esto obedece en parte a la falta de una formulación específica teórica y política de la posición de este tercer sector, así como también a su relativa falta de fuerza frente a las posiciones antes descritas. Mientras las teorías clásicas se pueden sustentar en la antagonía histórica entre Estado y privados y encuentran allí militantes y recursos, los usuarios, consumidores y comunidades carecen de dichos espacios y en el esquema tradicional son solo un subconjunto marginal del grupo "privados", y un subconjunto marginal del grupo de ideas "interés público".

En efecto, en esta discusión como en tantas otras vemos una matriz donde debería haber al menos tres posiciones divergentes, pero solo dos se encuentran efectivamente representadas en la discusión y respecto de esas dos es que se toma la decisión. La tercera posición, de la llamada sociedad civil, está habitualmente subrepresentada o incluso se pretende que sea coincidente con una de las dos anteriores, cuestión que habitualmente no es así.

Bien entiende y explica este problema el juez Breyer al señalar: Las leyes de regulación económica vienen del siglo pasado, y como ya he dicho se basaron en las leyes regulatorias de la época de la Reina Victoria en Inglaterra. Si uno lee esas leyes ve que solo las empresas tenían derecho a una audiencia pública y no se menciona a los consumidores. Mis alumnos me dicen: ;Pero eso es borroroso! ¿Por qué ofrecerle a la industria el derecho a una audiencia y no al público general?

36 Al hablar de "usuarios, consumidores y comunidades" me refiero a aquellas personas que o bien participan como compradores en un mercado regulado o en un mercado al que afecta la regulación, o bien sufren producto de alguna falla de mercado o falla de regulación. Incluyo en el grupo a aquellas personas que por cualquier motivo velen por los intereses difusos envueltos en la regulación de que se trate. La elección de esta nomenclatura obedece a dar cabida a aquellos nombres con los que más usualmente suele llamarse a estas personas. Deliberadamente excluyo a la llamada sociedad civil, no solo por la dificultad de dar con un concepto preciso para dicho grupo, sino también porque en ese concepto subyace cierto tipo de organización, el que si bien puede estar presente en los usuarios, consumidores o comunidades, no es presupuesto de ellas. 
La respuesta es que en aquel entonces nadie bubiera pensado que los consumidores deberian tener derecho a una audiencia pública, porque el regulador los representaba. El regulador representaba el interés público, y si había alguien que necesitaba protección ese era el ferrocarril. El objetivo de las audiencias era ser justo con el único interés privado que podía ser perjudicado, el de la industria. Sin embargo, después de 1968 esa manera de pensar sobre los asuntos regulatorios cambió, en parte por una creciente desconfianza en el gobierno. Y se hizo natural pensar que como no se podía confiar ni en el gobierno ni en el regulador para la protección del interés de los consumidores, era mejor confiar en los procedimientos y en otros representantes. Los tribunales empezaron a estudiar las leyes y a desarrollar métodos para representar a los consumidores ${ }^{37}$.

El hecho de que este tercer sector se encuentre escasamente representado en la concepción de los Tribunales Administrativos Especiales tiene ciertas consecuencias negativas para el mismo, y que a la larga pueden ser consecuencias negativas para el sistema en general.

En primer lugar, la solución de los Tribunales Administrativos Especiales puesta en la balanza con la creación de una judicatura contenciosa administrativa o con la entrega del control de los actos administrativos a la justicia ordinaria, puede representar un problema de acceso a la justicia. Los procedimientos se vuelven mucho más especializados y por lo tanto se vuelve más costoso acceder a especialistas que puedan representar a usuarios, consumidores o comunidades frente a estos tribunales. En el mercado de los servicios legales la especialización tiene un alto costo y, además, por lo complejo que es para un abogado especializarse, hay también menos competencia. Así entonces, los usuarios, consumidores o comunidades tienen pocas posibilidades de elección a la hora de enfrentarse a estos temas y las que existan serán generalmente costosas. El problema se ve agravado por la falta de profundidad en el mercado, como veremos más adelante.

En segundo lugar, la dispersión de procedimientos complejiza el conocimiento de los mismos y si eso es posible observarlo a nivel de operadores del sistema, a nivel popular el desconocimiento es probablemente total. Como señala Luis Cordero, esta forma de abordar las controversias ha llevado a una gran dispersión institucional y procedimental, que permite sostener solo considerando las cuestiones contenciosas administrativas (las que enfrentan a ciudadanos con el Estado) que estos representan más de 160 procedimientos específicos y dada la actual tramitación legislativa estos solo aumentarán ${ }^{38}$. La consecuencia es un aumento en la dificultad para hacer valer ciertos derechos $y$, nuevamente, un probable aumento en los costos para hacerlos valer de manera adecuada.

En la medida en que las personas, los usuarios, consumidores o comunidades ni siquiera saben que existe una posibilidad de accionar o cómo se podrían llevar adelante esas acciones, lo más probable es que eviten la vía de los Tribunales Administrativos Especiales o que la descubran a destiempo, haciéndoles más difícil poner en movimiento su pretensión.

${ }^{37}$ Breyer, S., "Cómo y cuándo regular los servicios de utilidad pública", en Revista Estudios Públicos vol. 78, Santiago, 2000, pp. 40-41.

38 Cordero, L., “¿Nueva justicia económica?”, en El Mercurio Legal, 12 de mayo de 2011. 
En tercer lugar, está el riesgo de captura por la convivencia permanente entre los operadores de un Tribunal Administrativo Especial, que se convierte en un mercado de servicios jurídicos con muy poca profundidad debido a falta de especialistas en la realidad nacional. Así por ejemplo, los abogados y economistas que litigan ante el TDLC tienen altas probabilidades de pasar de un lado a otro del mesón y por tanto trabajar como abogados de los regulados, para el propio tribunal o para la Fiscalía Nacional Económica. Lo mismo es probable que ocurra en el Tribunal Ambiental, en relación con las empresas y estudios de abogados que más usen el sistema y la Superintendencia del Medio Ambiente.

El contacto permanente entre operadores y la conciencia de ellos sobre la poca profundidad del mercado es un problema por al menos dos consideraciones. La primera es porque va homogeneizando ciertos criterios, cuestión que si bien puede tener características positivas en relación con la certeza jurídica, también rigidiza la administración de justicia y puede ser especialmente perjudicial para los usuarios, consumidores y comunidades, subrepresentados en el sistema y por lo tanto con menor peso a la hora de discutir esos criterios antes de su homogenización.

La segunda es la conciencia de los operadores de que es muy probable pasar de un lado al otro del mesón en el corto plazo y que las opciones laborales existentes en el mercado son precisamente esas y muy pocas más. Esto provoca que la labor, especialmente de los tribunales y los reguladores, sean de menor calidad o al menos tengan mayor deferencia los unos con los otros ${ }^{39}$. En el caso de los operadores privados, hace menos probable que abogados y otros especialistas acepten representar a usuarios, consumidores o comunidades, por temor a represalias futuras de los regulados, quienes serán sus principales clientes.

Todos esos riesgos conspiran contra los objetivos declarados de los Tribunales Administrativos Especiales y dicen relación con la adopción de esta solución ecléctica de acuerdo entre las visiones contrapuestas. Parecería interesante que estas consideraciones fueran tomadas en cuenta a la hora de continuar con la creación de este tipo de organismos.

\section{CONCLUSIÓN}

Como vimos, el derecho chileno no ha dado solución real al problema del control judicial de los actos administrativos, y como señala Ferrada, abora bien, para que los particulares puedan satisfacer esta carga y proteger sus derechos o intereses, el ordenamiento jurídico

${ }^{39}$ La Captura del Regulador es definida por el Oxford Dictionary of Economics como la tendencia del regulador a identificarse con los intereses de la industria que se supone debe regular. Esto sucede cuando un regulador encargado de regular una determinada industria en aras del interés público, identifica ese interés público con el interés de los productores en esa industria, en lugar de con el interés de los consumidores o del público en general. Black, J. Nigar, H. y Gareth M., "Oxford Dictionary of Economics”, 3era edición, 2009, Oxford University Press, New York. p. 384. 
debe proveer de mecanismos eficaces para impugnar estos actos, discutiendo la validez de los mismos y paralizando, en su caso, su ejecutividad y ejecutoriedad ${ }^{40}$.

En ese sentido, la creación de Tribunales Administrativos Especiales es una forma ecléctica pero efectiva de solucionar el conflicto planteado. En un trabajo anterior, Bordalí identifica las principales opciones de solucionar el problema del control judicial o la justiciabilidad de los actos administrativos. Una primera opción sería crear tribunales independientes dentro de las agencias administrativas autónomas, al estilo del derecho anglosajón. La segunda es crear dentro de la Administración actual tribunales independientes e imparciales. La tercera sería atribuir a los juzgados civiles la potestad de juzgar los actos administrativos y la cuarta la creación de tribunales de lo contencioso-administrativo ${ }^{41}$.

La solución actual de nuestro derecho se mueve entre los números dos y tres anteriores, precisamente dando muestras de ese espíritu de consenso. En el contexto político, la creación de Tribunales Administrativos Especiales parece adecuada, pero no debemos olvidar que conlleva riesgos respecto de la tercera parte en esta relación, y que es la menos considerada a la hora de estudiar las posibles soluciones.

En efecto, aunque en general los teóricos de la luz roja se refieran a la justiciabilidad de los actos administrativos como algo necesario para resolver los problemas que se dan entre la administración y los administrados, ello solo funciona de manera absoluta en la medida en que esa relación no tenga un carácter relevante para terceros, cosa que difícilmente puede darse en temas de "especial carácter técnico".

Si partimos de la base misma de la regulación, en el concepto predominante de ella que la ve como una manera de resolver las fallas de mercado y observamos que las fallas de mercado no son otra cosa que la ineficiencia del mismo para asignar bienes ${ }^{42}$, podremos concluir que allí donde hay regulación hay o hubo una falla y por lo tanto ineficiencia.

Luego, si de la regulación resulta un acto administrativo este probablemente alterará la relación entre las partes de un mercado intentando solucionar dicha falla. Generalmente esta solución pasará por una imposición a la industria como administrado-regulado, que importará el cumplimiento de ciertos estándares por su parte. La administración espera que ese estándar haga más eficiente el mercado y por lo tanto satisfaga el interés del usuario o consumidor.

Por lo tanto, si el administrado regulado (la industria) reclama de la legalidad de esa medida tomada como solución a la falla de mercado, no solo estará comprometido su interés y el del Estado, sino que también el de los usuarios, consumidores o comunidades. De la misma manera, el estándar puede no satisfacer la necesidad de solución de una falla y por lo tanto puede ser considerado ilegítimo por los usuarios, consumidores

${ }^{40}$ Ferrada, J., "Los Procesos Administrativos en el Derecho Chileno”, en Revista de Derecho de la Pontificia Universidad Católica de Valparaíso, vol. XXXVI, Valparaíso, 2011, p. 252.

41 Bordalí, A. Ob. Cit. p. 33.

${ }^{42}$ Baldwing, R., Cave, M.y Lodge, M., Ob. Cit., pp. 15-24. 
o comunidades. Por último, sería un error confundir el interés del Estado con el de los usuarios, consumidores o comunidades, ya que hoy ellos no necesariamente coinciden.

Debido a todo lo anterior, lo que se extraña en la solución que hemos analizado es esta tercera mirada, pues en general la creación de Tribunales Administrativos Especiales no amplía realmente las posibilidades de acceder a la justicia por parte de los usuarios, consumidores y comunidades, pudiendo incluso restringirla.

Así entonces, aun cuando en consideración del escenario anterior a la creación de Tribunales Administrativos Especiales, podríamos considerar que hay una mejora, de la misma manera pareciera que la creación de una base más amplia que abaratase los costos y dificultara la captura sería una solución más eficiente a los problemas administraciónadministrado, no siendo necesario discutir la creación de nuevos órganos para cada nueva dificultad que se ponga en la agenda.

La subrepresentación de los usuarios, consumidores o comunidades no es por supuesto un tema que tenga solamente que ver con los Tribunales Administrativos Especiales, pero sí es esta un área donde se requiere, a la hora de diseñar organismos y también a la hora de utilizarlos, tener conciencia de que existe un interés importante y difuso de este grupo de personas, el que probablemente no será adecuadamente representado durante la discusión y al que hay que poner atención.

Por lo mismo, creemos que la creación de Tribunales Contencioso-Administrativos sería a la larga una solución mejor, no solo por la gran cantidad de otras materias que permitiría conocer y por el orden que se le daría a los actuales sistemas de solución de estas controversias, sino que también para armonizar el funcionamiento de estos Tribunales Administrativos Especiales ya creados.

\section{BIBLIOGRAFÍA}

Baldwing, R., Cave, M. y Lodge, M., Understanding Regulation. Theory, Strategy and Practice, $2^{\text {nd }}$ Ed. Oxford University Press, Oxford, 2012.

Black, J., Nigar, H. y Gareth M., Oxford Dictionary of Economics, $3^{\text {era }}$ edición, 2009, Oxford University Press, New York.

Bordalí, A., "La Administración Pública ante los Tribunales de Justicia Chilenos". En Revista Chilena de Derecho, Pontificia Universidad Católica de Chile, Vol. XXXIII, Nº 1, Santiago, 2006.

Breyer, S., "Cómo y cuándo regular los servicios de utilidad pública”, en Revista Estudios Públicos vol. 78, Santiago, 2000.

Cordero, L., El Control de la Administración del Estado, Legal Publishing, $2^{\circ}$ Edición, Santiago, 2009.

Cordero, L., “¿Nueva justicia económica?”, en El Mercurio Legal, 12 de mayo de 2011.

Cordero, L. y García, J.F., "Elementos para la discusión de Agencias Independientes en Chile”, en Anuario de Derecho Público, Universidad Diego Portales., Santiago, 2012, páginas 415-435.

ENtReVista a Rubén Ballesteros. Disponible en http://www.pulso.cl/noticia/empresa-mercado/ empresa/2013/06/11-23893-9-ruben-ballesteros-lo-deseable-es-que-las-materias-ambientalesse-resuelvan-en.shtml [última vista 26 de julio de 2013]. 
Fernández T. y García de Enterría, E., Curso de Derecho Administrativo, Tomo I, 1 era edición, Civitas Ediciones, Buenos Aires, 2006.

Ferrada, J.C., "Los Tribunales que ejercen la justicia administrativa en el derecho chileno", en Arancibia Mattar y otros. (coord.), Litigación Pública, Thomson Reuters, Santiago, 2011.

Ferrada, J.C., "Justicia Administrativa y Principio de Separación de Poderes", en Estudios de Derecho Público, Actas de las XL Jornadas de Derecho Público, Legal Publishing, Santiago, 2010.

Ferrada, J.C., "Los Procesos Administrativos en el Derecho Chileno", en Revista de Derecho de la Pontificia Universidad Católica de Valparaíso, vol. XXXVI, Valparaíso, 2011.

Faúndez J., Democratización, Desarrollo y Legalidad, Ediciones Diego Portales, Santiago, 2011.

GaLindo, M., "Sobre el control jurisdiccional de la discrecionalidad técnica a través del recurso de protección”, en Revista de Derecho Ambiental, vol. I, Facultad de Derecho Universidad de Chile, Santiago, 2003.

Greiber, B., Ocampo, L. y Seguel, L., "Justicia Tributaria y delegación de facultades jurisdiccionales: Análisis de la Jurisprudencia reciente del Tribunal Constitucional”, en Sentencias Destacadas 2006, Instituto Libertad y Desarrollo, Santiago, 2006.

Juica, M. Discurso de Inauguración año judicial 2011. Disponible en http://www.pjud.cl/ PDF/Prensa_Com/CuentaPublica/discurso2011/discurso_1_de_marzo_2011.pdf?opc_ menu=0\&opc_item $=1$ [última vista 30 de julio de 2012].

MARÍn, U., "Vigencia actual de la invalidación de los actos administrativos", en Revista de Derecho del Consejo de Defensa del Estado, No 2, Santiago, 2002.

Mendoza, R., "Acerca del control de la discrecionalidad técnica en materia eléctrica" en Revista Chilena de Derecho, vol. XXV, Pontificia Universidad Católica de Chile, Santiago, No 3, 1998.

MontT, S., "Autonomía y responsividad: Dos expresiones de la vocación judificadora del Derecho Administrativo y sus principios fundamentales". Documento de Trabajo para el Centro de Regulación y Competencia de la Facultad de Derecho de la Universidad de Chile, 2010. Disponible en http:/www.regcom.uchile.cl/assets/files/Informes\%20y\%20Papers/ Documento\%20de\%20trabajo\%204.pdf [última vista $1^{\circ}$ de agosto de 2012].

PIerry, P., "El control de la Discrecionalidad Administrativa", en Revista de Derecho de la Pontificia Universidad Católica de Valparaíso, vol. VII, Valparaíso, 1984.

Parejo, L. Administrar y Juzgar: dos funciones constitucionales distintas y complementarias, Tecnos, Madrid, 1993.

SaAvedra, R., Discrecionalidad Administrativa, Abeledo Perrot, Santiago, 2011.

Vergara, A., "Esquema del Contencioso-Administrativo: Su tendencia hacia un modelo mixto", en Arancibia Mattar y otros. (coord.), Litigación Pública, Thomson Reuters, Santiago, 2011, p. 42. 